\title{
Posttransplant ruxolitinib combined with cyclophosphamide for graft versus host disease prophylaxis and relapse prevention in patients with myelofibrosis
}

Maria V. Barabanshikova, Ivan S. Moiseev, Elena V. Morozova, Julia J. Vlasova, Vadim V. Baykov, Ildar M. Barkhatov, Boris V. Afanasyev

Raisa Gorbacheva Memorial Institute of Children's Oncology, Hematology and Transplantation First I. Pavlov State Medical University of St. Petersburg

Contact: Dr. Maria V. Barabanshikova

E-mail: mashaprian@mail.ru

\section{Introduction}

Myelofibrosis (MF) is a BCR-ABL-negative myeloproliferative disorder with progressive clinical course and usually poor prognosis. Allogeneic stem cell transplantation (alloHSCT) is currently the only treatment modality with curative potential in patients with MF. JAK1/JAK2 inhibitor ruxolitinib is effective in decreasing symptomatic splenomegaly and myelofibrosis-related symptoms. At the same time, it shows a significant immunomodulatory effect and is widely used for the treatment of acute and chronic GVHD. In our study, we administered ruxolitinib with posttransplant cyclophosphamide for GVHD prophylaxis and relapse prevention.

\section{Patients and methods}

We analyzed the results of alloHSCT in 4 patients aged 36-52 (median 41) years. One patient was diagnosed with post-essential thrombocythemia myelofibrosis, and three cases of primary myelofibrosis. By DIPSSplus, 2 patients had intermediate- 2 and 2 patients had a high-risk disease. 3 patients were JAK2V617F positive, 1 patient was MPL-positive before alloHSCT. All the patients were treated with JAK1/2 inhibitors before alloHSCT, with median treatment duration of 6 months ( 3 to 18). Disease stabilization occurred in two cases, and two other patients achieved clinical improvement. In one patient, splenectomy was performed, due to poor spleen response. A reduced-intensity conditioning (Fludarabine $180 \mathrm{mg} / \mathrm{m}^{2}$ plus Busulfan $8-10 \mathrm{mg} / \mathrm{kg}$ ) followed by alloHSCT from full-matched (3) and mismatched (HLA 9/10)
(1) unrelated donor was performed. Graft-versus-host disease prophylaxis consisted of posttransplant cyclophosphamide $100 \mathrm{mg} / \mathrm{kg}$ at day $+3,+4$ and ruxolitinib (5 to $7,5 \mathrm{mg}$ bid from day +5 until day +50 (2), and day +100 (2). G-CSF mobilized peripheral blood progenitor cells were used as a stem cell source. Median number of CD34+cells $/ \mathrm{kg}$ was $6.7 \times 10^{6}(1.4$ to 7.3$)$. The trial is registered on clinicaltrials. gov, NCT02806375.

\section{Results}

Primary engraftment was documented in 4 patients. Median time to the leukocyte engraftment was 34 (19-79) days, to platelets' engraftment, 57 days (20-112). 2 patients developed cytomegalovirus reactivation and were successfully treated with Gancyclovir. 2 patients experienced polyomavirus infection. We did not document any severe episodes of toxicity during ruxolitinib therapy in early posttransplant period. Four patients achieved hematological remission (splenomegaly reduction and constitutional symptoms resolution), molecular remission and full donor chimerism. a near-complete resolution of bone marrow fibrosis was observed in two patients (from grade 3-2 down to grade 1-0) accompanied by molecular remission and full donor chimerism. Two patients developed acute GVHD grade II and moderate overlap GVHD with skin and liver involvement after ruxolitinib discontinuation. GVHD resolved completely after cyclosporine A administration. None of the patients required steroid therapy. All patients are alive without any signs of disease progression with median follow-up of 5 months. 


\section{Conclusion}

AlloHSCT is an effective treatment modality for myelofibrosis. Post-transplant JAK1/2 inhibition in combination with post-transplant Cyclophosphamide seems a promising therapeutic option to prevent GVHD and relapse. The trial will continue to recruit patients.

\section{Keywords}

Myelofibrosis, allogeneic hematopoietic cell transplantation, Ruxolitinib, Cyclophosphamide.

\section{Опыт применения посттрансплантационного циклофосфамида в комбинации с руксолитинибом в качестве профилактики реакции трансплантат против хозяина и рецидива у пациентов с миелофиброзом}

Мария В. Барабанщикова, Иван С. Моисеев, Елена В. Морозова, Юлия Ю. Власова, Вадим В. Байков, Ильдар М. Бархатов, Борис В. Афанасьев

Научно-исследовательский институт детской онкологии, гематологии и трансплантологии им. Р. М. Горбачевой, Первый Санкт-Петербургский государственный медицинский университет им. И.П. Павлова

\section{Введение}

Миелофиброз относится к хроническим BCR-ABL-негативным миелопролиферативным неоплазиям и сопровождается, как правило, непрерывно прогрессирующим течением. Аллогенная трансплантация гемопоэтических стволовых клеток в настоящее время является единственным методом терапии, позволяющим добиться излечения от заболевания. Применение ингибитора JAK1/JAK2 руксолитиниба во многом позволяет изменить статус заболевания на момент алло-ТГСК - уменьшить спленомегалию, конституциональные симптомы, улучшить гематологические показатели. В то же время руксолитиниб обладает иммуномодулирующим эффектом, благодаря чему широко используется для лечения острой и хронической РТПХ. В нашем исследовании мы использовали руксолитиниб в комбинации с посттрансплантационным циклофосфаном в качестве профилактики РТПХ и рецидива заболевания.

\section{Материалы и методы}

Мы проанализировали результаты алло-ТГСК у 4 пациентов в возрасте от 36 до 52 лет (медиана 41 год). У трех пациентов был диагностирован первичный миелофиброз, у 1 пациента - посттромбоцитемический миелофиброз. Двое пациентов относились к промежуточному-2 риску по шкале DIPSSplus, двое - к высокой группе риска. У 3 пациентов отмечалась мутация JAK2V617F, у одного - мутация в гене MPL. 4 пациента получали терапию руксолитинибом в качестве предтрансплантационной подготовки, медиана длительности терапии составила 6 месяцев (3-18). У двух пациентов отмечалось клиническое улучшение, у двух других - стабилизации заболевания на момент алло-ТГСК. Одному пациенту была выполнена спленэктомия в связи с выраженной спленомегалией и недостаточным ответом со стороны селезенки. У всех пациентов применялся режим кондиционирования со сниженной интенсивностью доз (флударабин 180 мг/м², бусульфан 10 мг/кг). Троим пациентам алло-ТГСК была выполнена от HLA-совместимого донора (10/10), одному больному - от частично-совместимого донора (9/10). В качестве профилактики РТПХ использовался циклофосфамид 50 мг/кг в день $+3,+4$ и руксолитиниб 5-7,5 мг $\times 2$ раза в сутки с дня +5 по день $+50(2)$ и день $+100(2)$. Медиана количества CD34+-клеток составила $6,7 \times 10^{6}(1,4-7,3)$. Исследование зарегистрировано на clinicaltrials.gov, NCT02806375.

\section{Результаты}

Приживление трансплантата было зарегистрировано у всех больных. Медиана времени до приживления по лейкоцитам составила 34 дня (19-79), по тромбоцитам 57 дней (20-112). У 2 пациентов отмечалась реактивация цитомегаловирусной инфекции с положительны ответом на фоне противовирусной терапии. В остальном мы не отмечали серьезных эпизодов токсичности на фоне 
терапии руксолитинибом в раннем посттрансплантационном периоде. У 4 пациентов была достигнута клинико-гематологический ответ (уменьшение размеров селезенки, исчезновение конституциональных симптомов), молекулярная ремиссия, полный донорский химеризм. У пациентов отмечался регресс фиброза в костном мозге со степени 2-3 до 0-1 (по шкале 0-3), что сопровождалось достижением молекулярной ремиссии и полного донорского химеризма. У двух пациентов отмечалось развитие острой РТПХ 2 степени и РТПХ по типу overlap-синдрома средней степени тяжести после отмены руксолитниба. Проявления РТПХ разрешились на фоне терапии циклоспорином А, при этом не требовалось назначения системных глюкокортикостероидов. В настоящее время все пациенты живы, находятся в ремиссии заболевания, медиана наблюдения составила 5 месяцев.

\section{Заключение}

Алло-ТГСК является эффективной терапевтической опцией для пациентов с миелофиброзом. Посттрансплантационный циклофосфамид в комбинации с руксолитинибом представляется эффективной терапевтической опцией в качестве профилактики РТПХ и рецидива заболевания. В дальнейшем мы планируем продолжить набор пациентов в исследование.

\section{Ключевые слова}

Миелофиброз, аллогенная трансплантация гемопоэтических клеток, Руксолитиниб, циклофосфамид. 